\title{
CHARACTERIZATION OF THE GRAINS IN 2014 ALUMINIUM ALLOY AFTER EQUAL CHANNEL ANGULAR EXTRUSION (ECAE) PROCESS
}

\author{
SONIA BocZKAL, MARZENA LECH-GREGA, WoJCIECH SZYMAŃSKI \\ Institute of Non-Ferrous Metals, Light Metals Division, ul. Piłsudskiego 19, 32-050 Skawina, Poland \\ e-mail: zwboczka@cyf-kr.edu.pl,zwlech@cyf-kr.edu.pl,zwszyman@cyf-kr.edu.pl \\ (Accepted December 23, 2006)
}

\begin{abstract}
In 2014 alloy deformed by Equal Channel Angular Extrusion process (ECAE) the changes in the size and shape of structural constituents were examined. The samples subjected after deformation to additional annealing at $300^{\circ} \mathrm{C} / 10 \mathrm{~min}$ were characterized by larger grains of nearly-equiaxial shapes. The microstructure after deformation was composed of a large number of the mutually crossing bands and microbands. The intersection of microbands resulted in formation of rectangular and rhombohedral grains. It was noted that the average grain size after $\varepsilon=4.6$ (4 passes) was $0.2 \mu \mathrm{m}$.
\end{abstract}

Keywords: aluminium alloy, grain refinement, high deformation, shape factor.

\section{INTRODUCTION}

The application of high plastic deformations produces structure with the grain size below $0.5 \mu \mathrm{m}$ (Valiev et al., 1993; Iwahashi et al., 1998; Sun et al., 2000; Richert et al., 2003). Thus obtained grain refinement results in a considerable increase of mechanical properties. In terms of plastic working, the property specially important in ultrafine-grained/ nanocrystalline materials is rapid increase of their plastic behaviour observed after application of very large deformations (Valiev, 2003).

One of the means to obtain high plastic deformations is the method according to which a sample undergoes deformation through extrusion in an angular die (ECAE - Equal Channel Angular Extrusion process) (Segal, 1995). A mechanism, which during the deformation is responsible for the formation of new and fine grains, is the mutually crossing of macroand microbands (Belyakov et al., 2001; Richert et al., 2003). In pure aluminium, in spite of the fact that the structure of a sample after deformation is characterized by the presence of shears bands and microbands of a very high density, the newly formed grains observed under transmission electron microscope (TEM), are of an equiaxial shape (Iwahashi et al., 1998; Sun et $a l ., 2000)$. The formation of those, nearly equiaxial, grains in pure aluminium may be due to:

- effect of temperature during deformation which may initiate the dynamic processes of structure recovery.
- high energy of the stacking fault which accelerates the initiation of the processes of recovery and polygonization (Richert, 1990; Bay et al., 1992) .

The structure of aluminium alloys after deformation is characterized by the presence of rectangular grains of rhombohedral shapes. Within the low range of strains $(\varepsilon<1)$, the boundaries of the newly formed grains are composed of dislocation tangles of a very high density - under these conditions, the dislocation cells are forming. (Bay et al., 1992). With growing deformation, the number of the mutually crossing microbands is growing, too. A considerable increase of deformation makes the grain boundaries, so far composed of dislocation tangles, get transformed into the grain boundaries with the, so called, "fuzzy contrast" or being in non-equilibrium configuration (Valiev et al., 1993; Morris et al. 2002). The shape of the grains also changes from rectangular, rhombohedral into almost equiaxial. This is visible specially during analysis of the length and width of grains (Morris et al. 2002). However, the change does not take place immediately within the whole volume of material but after a significantly deformation (Valiev et al., 1993; Richert et al. 2003).

In some aluminium alloys, i.e., in those that are deformation-hardened, it is necessary to carry out an inter-operational softening annealing between the successive passes of ECAE. The annealing reduces the hardness of material and makes the grains grow in size and change their shape. The grain growth is, 
however, impeded by the precipitates present in the alloy (Morris et al., 2002).

An ideal structure would be that of very fine, equiaxial grains of the size comprised in a narrow range of 0.1 to $0.3 \mu \mathrm{m}$. An aluminium alloy with a structure like this would render to plastic forming quite easily by engagement in its structure of the mechanisms of superplastic flow.

The aim of the present studies was to determine changes in distribution of the grain size and shape during ECAE and softening annealing in alloy 2014. The adopted process regime resulted in manufacturing a material of the structure composed of almost equiaxial grains of ultrafine dimensions.

\section{MATERIALS AND METHODS}

Studies were conducted on 2014 aluminium alloy of the chemical composition given in Table 1. The base material was samples of extruded bars of $\phi 20$ $\mathrm{mm}$ diameter after homogenizing treatment $\left(500^{\circ} \mathrm{C} / 8 \mathrm{~h}\right)$. The average hardness of the samples after homogenization was $57.4 \mathrm{HB}$.

Table 1. Chemical composition of 2014 alloy [wt.\%].

\begin{tabular}{cccccccc}
\hline $\mathrm{Fe}$ & $\mathrm{Si}$ & $\mathrm{Cu}$ & $\mathrm{Zn}$ & $\mathrm{Ti}$ & $\mathrm{Mn}$ & $\mathrm{Mg}$ & $\mathrm{Al}$ \\
0.09 & 0.76 & 4.23 & 0.01 & 0.02 & 0.57 & 0.33 & rest \\
\hline
\end{tabular}

The process of ECAE was conducted using equipment designed and made by IMN OML Skawina and a vertical press of $60 \mathrm{~T}$ capacity. During the angular extrusion at ambient temperature, the samples for successive passes were turned by $90^{\circ}$ to around extrusion axis.

Four samples were assigned for deformation tests, within the range of true strains $\varepsilon=1.15-4.6$ ( 1 pass equal to $\varepsilon=1.15$ ).

After true strains $\varepsilon=2.3$ ( 2 passes) and $\varepsilon=4.6$ (4 passes) the samples were annealed at a temperature of $300^{\circ} \mathrm{C}$ for 10 minutes and cooled in water. The purpose of the annealing was softening of the material. The samples were prepared for observations under the light and transmission electron microscopes.

Polished sections and thin foils were prepared parallel to the extrusion axis. The grains were revealed by Barcker's reagent for light microscope observations.
Using Aphelion - an image analysis program, the average grain size, observed under TEM in samples after 2 passes deformed by $\varepsilon=2.3$, annealing, $\varepsilon=4.6$ (4 passes), and reannealing was measured. In four samples the shape factor depending on the grain size was examined. The shape factor (difference between the lengths of the major and minor axes of the best elipse fit, divided by the sum of the lengths) equals to zero means an ideal circle, and a unit means an intercept line.

The contours of grain boundaries on TEM images were drawn manually. The images were next scanned and subjected to analysis on Aphelion program. By properly selecting the threshold of detection, the grain boundaries were extracted from the calibrated base image. Next, by geometrical and morphological operations, the noise and other defects (e.g. "holes") were removed. The next step consisted in conversion of the image elements into objects, and parameters, such as surface area and shape factor, were measured. By graphically depicting the analysed objects against the background of the input image it was possible to evaluate if the analysis has been done correctly. The number of the examined grains was approximately 350 in every case.

The hardness measurements were taken by Brinell method.

\section{RESULTS}

The structure of 2014 alloy deformed by ECAE process is characterized by the presence of shear bands of high density (Fig. 2). The deformation within the range of high plastic strains results in refinement of granular structure. The microstructure observed under the TEM reveals a high density of dislocations inside and on the boundaries of microbands (Fig. 2). Due to mutually crossing of the microband families, some dislocation cells are formed, and with the increasing strain - new grain boundaries are produced. The boundaries of the mutually crossing microbands are at the same time acting as boundaries to the newly formed grains. The image of microstructure changes after annealing of the deformed sample at $300^{\circ} \mathrm{C} / 10 \mathrm{~min}$. The structure shows the presence of grains assuming equiaxial shapes (Fig. 2). Besides shape, also the size distribution changes, and some grains from the size range of 0.5 to $0.8 \mu \mathrm{m}$ appear as well (Fig. 1). It was observed that after annealing the mean grain size grew by $0.1 \mu \mathrm{m}$, compared with the grains in sample after $\varepsilon=2.3$ (2 passes). The grain shape in function of area, expressed 
by the shape factor, is shown in Fig. 3. The difference in grain distribution between sample after $\varepsilon=2.3$ (2 passes) and sample after additional annealing is small (Fig. 3a,b). The only difference seems to be a smaller number of rectangular grains in sample after additional annealing. In sample after $\varepsilon=2.3$ ( 2 passes) the fine grains from the range of 0 to $0.08 \mu^{2}$ are characterized by the shapes more oval than the grains of an area larger than $0.08 \mu \mathrm{m}^{2}$ (Fig. 3a). This testifies the refinement of microband structure due to mutually crossing. In the place of intersections, the boundaries of microbands form grains of rhombohedral shapes. The process of plastic deformation conducted until $\varepsilon=4.6$ (4 passes) results in further grain refinement. Compared to 2 passes, the average grain size remains mostly the same as well as hardness (Fig. 4). The properties after $\varepsilon=2.3$ (2 passes) are already well stabilized and increasing the number of passes does not result in further increase of these properties. Fig. 3c shows a histogram of shape factors in function of the grain area in samples group after $\varepsilon=4.6$ ( 4 passes). Within the range of grain areas from 0.04 to $0.08 \mu \mathrm{m}^{2}$ some rectangular grains appear, while within the range of 0.08 to $0.16 \mu \mathrm{m}^{2}$ the grains assume more equiaxial shapes. Additional annealing at $300^{\circ} \mathrm{C} / 10 \mathrm{~min}$ after $\varepsilon=4.6$ ( 4 passes) has made the effects of a recovery process more prominent in the structure. In the structure observed under the light microscope very fine grains of a large angle of misorientation are noted (Fig. 2). The band structure is blurred. An obvious decrease in the number of rectangular grains is also visible in the histogram (Fig. 3d). The observations carried out under the TEM revealed the presence of equiaxial grains after $\varepsilon=4.6$ ( 4 passes) and re-annealing (Fig. 2 ). The sample after $\varepsilon=2.3$ ( 2 passes) and annealing was composed in prevailing part of rectangular grains; their boundaries were "bulging". This has affected the run of histograms showing changes in the shape factor. The values of an average grain size and of the shape factor are given in Table 2. An average grain size in sample after $\varepsilon=4.6$ (4 passes) and reannealing has remained much the same, compared with sample after $\varepsilon=2.3$ ( 2 passes) and annealing.
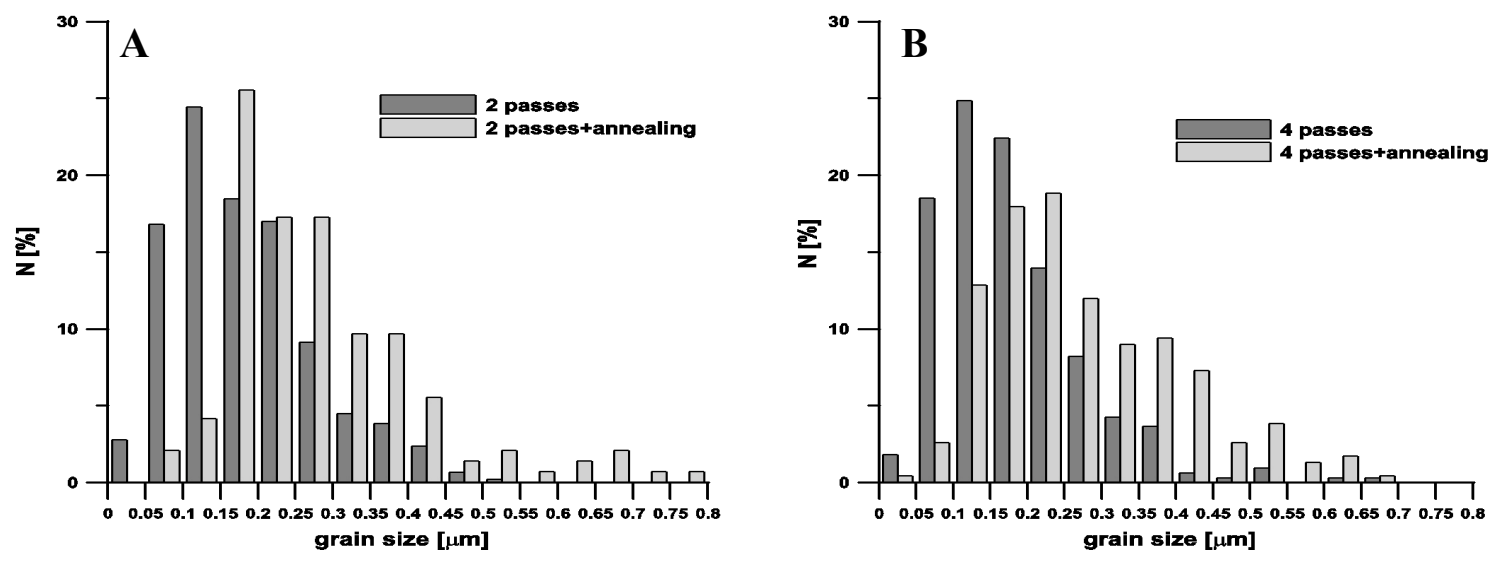

Fig. 1. Histograms of grain size distribution in samples after $\varepsilon=2.3$ (2 passes) (a) and $\varepsilon=4.6$ (4 passes) (b) and annealing at $300^{\circ} \mathrm{C} / 10 \mathrm{~min}$.

Table 2. Grain size ECAE - deformed and annealed.

\begin{tabular}{ll}
\hline Material state & Average grain size $[\mu \mathrm{m}]$ \\
\hline$\varepsilon=2.3(2$ passes $)$ & 0.20 \\
$\varepsilon=2.3+$ annealing at $300^{\circ} \mathrm{C} / 10 \mathrm{~min}$ & 0.32 \\
$\varepsilon=4.6$ (4 passes) & 0.20 \\
$\varepsilon=4.6(4$ passes $)+$ annealing at $300^{\circ} \mathrm{C} / 10 \mathrm{~min}$ & 0.30 \\
\hline
\end{tabular}




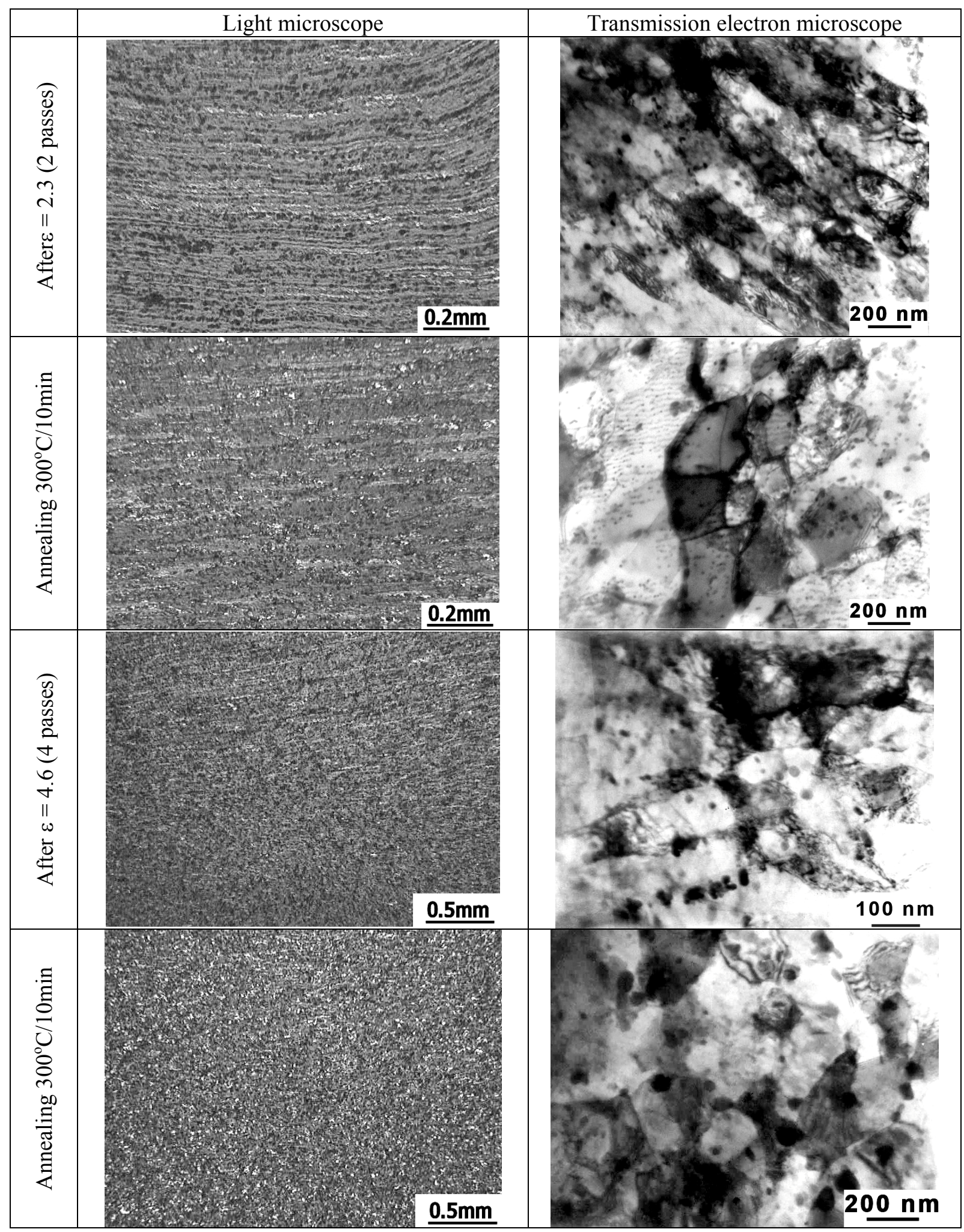

Fig. 2. Structure of 2014 alloy after $\varepsilon=2.3$ and $\varepsilon=4.6$ (ECAE) and intermediate annealing. 

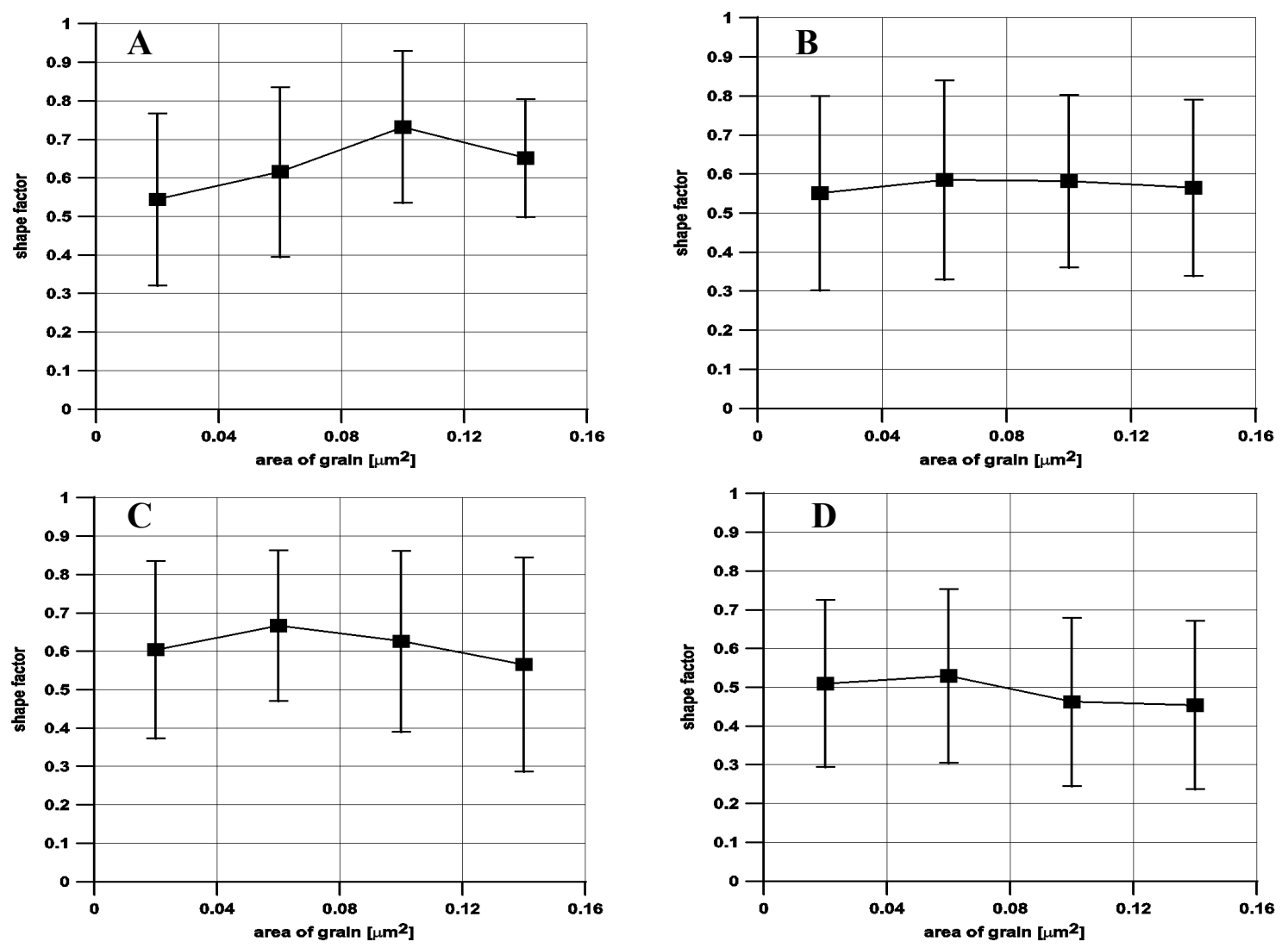

Fig. 3. Grain shape factor in samples after $\varepsilon=2.3$ (2 passes) (a) and annealing at $300{ }^{\circ} \mathrm{C} / 10 \mathrm{~min}$ (b) and $\varepsilon=4.6$ (4 passes) (c) and annealing at $300^{\circ} \mathrm{C} / 10 \mathrm{~min}(d)$.

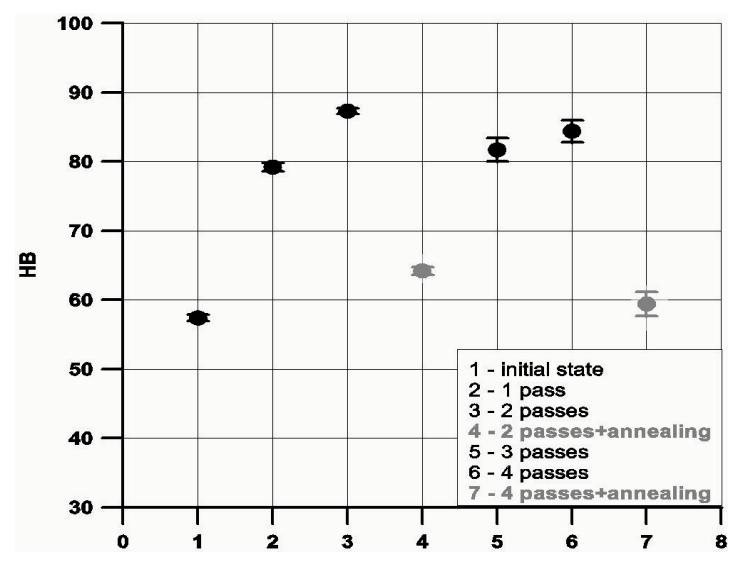

Fig. 4. Hardness after ECAE and intermediate annealing.

\section{DISCUSSION}

The reason of any changes in the grain size may be attributed to a high value of the energy accumulated in material after $\varepsilon=4.6$ ( 4 passes) which, during annealing, gives rise to the process of recovery. Some new grains are forming along the band boundaries and in the zones characterized by a high density of dislocations. The next reason accounting for the absence of any changes in the grain size may be a large number of the precipitates in alloy which during annealing are effectively blocking any migration along the grain boundaries. Due to this, the dislocation boundaries of new grains are blocked, and in their interior the dislocations are annihilated. 


\section{CONCLUSIONS}

1. The deformation of 2014 alloy by ECAE process results in grain refinement. The size of grains after true strain $\varepsilon=4.6$ ( 4 passes) reduced to $0.18 \mu \mathrm{m}$.

2. The new grains, which are forming due to mutually crossing of the bands and microbands, are characterized by rectangular shapes.

3. Annealing at $300^{\circ} \mathrm{C} / 10 \mathrm{~min}$ after deformation affects the shape of the newly formed grains. The boundaries of grains after $\varepsilon=2.3$ ( 2 passes) and annealing are „bulging” because of the process of recovery and polygonization going on in the alloy. On the other hand, the boundaries of grains after $\varepsilon=4.6$ ( 4 passes) and reannealing form the shape of polygons.

4. An average size of grains after $\varepsilon=2.3$ (2 passes) and after $\varepsilon=4.6$ ( 4 passes) is similar. In sample after $\varepsilon=4.6$ (4 passes) and reannealing, where the accumulated energy was higher than in the sample after $\varepsilon=2.3$ ( 2 passes) and annealing, the processes of recovery and/or arresting of the migrating grain boundaries on the precipitates were observed to occur.

\section{ACKNOWLEDGEMENTS}

The authors wish to thank Messrs. J. Senderski and B. Płonka for assistance rendered in collecting the results of investigation. This work was supported by the Polish Committee of Scientific Research under grant no. PBZ-KBN-096/T08/2003.

\section{REFERENCES}

Bay B, Hansen N, Hughes DA, Kuhlmann-Wilsdorf D (1992). Evolution of f.c.c. deformation structures in polyslip. Acta mater 40(2):205-19.

Belyakov A, Sakai T, Miura H, Tsuzaki K (2001). Grain refinement in copper under large strain deformation. Phil Magazine A:1-15.

Iwahashi Y, Horita Z, Nemoto M, Langdon TG (1998). The process of grain refinement in equal channel angular pressing. Acta mater 46(9):3317-31.

Morris DG, Munoz-Morris MA (2002). Microstructure of severely deformed $\mathrm{Al}-3 \mathrm{Mg}$ and its evolution during annealing. Acta mater 50:4047-60.

Richert M (1990). The effect of unlimited cumulation of large plastic strains on the structure-softening processes of 99.999 Al. Mat Science Eng A129:1-10.

Richert M, Richert J, Zasadziński J, Hawryłkiewicz S, Długopolski J (2003). Effect of large deformation on the microstructure of aluminium alloys. Mat Chemistry Phys 81:528-30.

Segal VM (1995). Materials processing by simple shear. Mat Science Eng A197:157-64.

Sun PL, Kao PW, Chang CP (2000). Characteristics of submicron grained structure formed in aluminum by equal channel angular extrusion. Mat Science Eng A283:82-5.

Valiev RZ (2003). Paradoxes of severe plastic deformation. Advanced Engineering Materials 5(5):296-300.

Valiev RZ, Korznikov AV, Mulyukov RR (1993). Structure and properties of ultrafine-grained materials produced by serve plastic deformation. Mat Science Eng A168:141-8. 